\title{
LETTER
}

\section{Mutation screening of RAD51C in male breast cancer patients}

\author{
Valentina Silvestri', Piera Rizzolo', Mario Falchetti', Ines Zanna², Giovanna Masala², Domenico Palli² and Laura Ottini*1 \\ See related research by Akbari et al., http://breast-cancer-research.com/content/12/4/404
}

We read with great interest the paper by Akbari and colleagues [1] in a recent issue of Breast Cancer Research. The authors reported on the absence of RAD51C mutations in 454 patients with $B R C A 1 / 2$-negative familial breast cancer/ovarian cancer $(\mathrm{BC} / \mathrm{OC})$. In the initial report by Meindl and colleagues [2], RAD51C mutations were identified in 6 out of 480 patients with $B R C A 1 / 2$ negative familial $\mathrm{BC} / \mathrm{OC}$. Interestingly, on the basis of histopathologic features, including intermediate grade (G2), estrogen receptor-positive $\left(E R^{+}\right)$, progesterone receptor-positive $\left(\mathrm{PR}^{+}\right)$, and HER2-negative (HER2-) expression, $R A D 51 C$-associated $\mathrm{BCs}$ were found to be similar to $B R C A 2$-associated $\mathrm{BCs}$ [2]. BRCA2 is known to play a significant role in male $B C(\mathrm{MBC})$; however, no occurrence of $\mathrm{MBC}$ was observed in the six $R A D 51 C$ families described [2].

To investigate the role of $R A D 51 C$ in $\mathrm{MBC}$, we screened for $R A D 51 C$ mutations in $97 \mathrm{MBC}$ patients selected from our population-based series of 126 cases because they were previously found negative for $B R C A 1 / 2$, CHEK2, $P A L B 2$, and BRIP1 mutations [3,4]. Notably, $25.8 \%$ of cases showed a positive first-degree family history of $\mathrm{BC}$ or $\mathrm{OC}$ or both. The majority of MBCs were invasive ductal carcinomas (74.5\%), G2 (53.5\%), $\mathrm{ER}^{+}(90.7 \%), \mathrm{PR}^{+}(82.6 \%)$, or HER2 ${ }^{-}(85.4 \%)$. Overall, $66 \%$ of the MBCs showed an $\mathrm{ER}^{+} / \mathrm{PR}^{+} / \mathrm{HER} 2^{-}$phenotype. All patients provided informed consent to the study. We carried out mutation screening of the nine exons and intron/exon boundaries of RAD51C by high resolution melting (HRM) analysis, a rapid closed-tube mutation scanning method with high sensitivity and specificity. Cases displaying abnormal profiles were evaluated by direct sequencing. Primers are available upon request.

We found no truncating RAD51C mutations. We identified a novel intronic variant, IVS3 $c .738-16 G>T$, in

\footnotetext{
*Correspodence: laura.ottini@uniroma1.it

'Department of Molecular Medicine, "Sapienza" University of Rome, Viale Regina Elena 324, 00161 Rome, Italy

Full list of author information is available at the end of the article
}

1 out of 97 MBCs (1\%). By in silico analysis, performed with Splice Site Prediction (Berkeley Drosophila Genome Project, Lawrence Berkeley National Laboratory, Berkeley, CA, USA) and NetGene 2 Server software (Center for Biological Sequence Analysis, Technical University of Denmark, Lyngby, Denmark), the IVS3 c.738-16G >T variant is predicted not to affect splicing. This variant was also identified in 2 out of 173 (1.2\%) population controls examined. We also found a neutral polymorphic intronic variant, IVS6 c. $904+34 T>C$ (rs28363318), in 16 out of 97 (16.5\%) MBCs.

Overall, our results, which are based on a relatively large $\mathrm{MBC}$ series, are consistent with the findings by Akbari and colleagues [1] and with data on 92 patients with hereditary gynecological cancer in which no deleterious $R A D 51 C$ mutations were identified [5] and would suggest that the impact of $R A D 51 C$ mutations on $\mathrm{BC}$ predisposition might be more limited than initially reported. In conclusion, we found no evidence that RAD51C mutations may contribute to MBC susceptibility. Further studies on larger MBC series are needed to confirm our findings.

\section{Abbreviations}

$B C$, breast cancer; ER, estrogen receptor; $G 2$, intermediate grade; $M B C$, male breast cancer; OC, ovarian cancer; PR, progesterone receptor.

\section{Competing interests}

The authors declare that they have no competing interests.

\section{Acknowledgments}

This letter was supported by a grant from Associazione Italiana per la Ricerca sul Cancro (AIRC IG 8713).

\section{Author details}

'Department of Molecular Medicine, "Sapienza" University of Rome, Viale

Regina Elena 324, 00161 Rome, Italy; ${ }^{2}$ Molecular and Nutritional Epidemiology Unit, Cancer Research and Prevention Institute - ISPO, Via Cosimo il Vecchio 2, 50139 Florence, Italy.

\section{Published: 8 February 2011}

\section{References}

1. Akbari MR, Tonin P, Foulkes WD, Ghadirian P, Tischkowitz M, Narod SA: RAD51C germline mutations in breast and ovarian cancer patients. Breast Cancer Res 2010, 12:404.

2. Meindl A, Hellebrand H, Wiek C, Erven V, Wappenschmidt B, Niederacher D, Freund M, Lichtner P, Hartmann L, Schaal H, Ramser J, Honisch E, Kubisch C, 
Wichmann HE, Kast K, Deissler H, Engel C, Müller-Myhsok B, Neveling K, Kiechle M, Mathew CG, Schindler D, Schmutzler RK, Hanenberg H: Germline mutations in breast and ovarian cancer pedigrees establish RAD51C as a human cancer susceptibility gene. Nat Genet 2010, 42:410-414.

3. Ottini L, Rizzolo P, Zanna I, Falchetti M, Masala G, Ceccarelli K, Vezzosi V, Gulino A, Giannini G, Bianchi S, Sera F, Palli D: BRCA1/BRCA2 mutation status and clinical-pathologic features of 108 male breast cancer cases from Tuscany: a population-based study in central Italy. Breast Cancer Res Treat 2009, 116:577-586.

4. Silvestri V, Rizzolo P, Falchetti M, Zanna I, Masala G, Bianchi S, Palli D, Ottini L: Mutation analysis of BRIP1 in male breast cancer cases: a population-based study in Central Italy. Breast Cancer Res Treat 2010 Dec 17. [Epub ahead of print]

5. Zheng Y, Zhang J, Hope K, Niu Q, Huo D, Olopade Ol: Screening RAD51C nucleotide alterations in patients with a family history of breast and ovarian cancer. Breast Cancer Res Treat 2010, 124:857-861.

doi:10.1186/bcr2823

Cite this article as: Silvestri V, et al: Mutation screening of RAD51C in male breast cancer patients. Breast Cancer Research 2011, 13:404. 